\title{
Using a Differential Pressure Sensor as Spirometer
}

\author{
Martin Augustynek, Ondrej Adamec, and David Micanik \\ VSB- Technical University of Ostrava, FEECS, Department of Cybernetics and Biomedical \\ Engineering, Ostrava, Czech Republic, 17. Listopadu 15, Ostrava - Poruba, 70833 \\ \{martin.augustynek, ondrej.adamec\}@vsb.cz
}

\begin{abstract}
For a doctor to determine the most accurate diagnosis of diseases of the respiratory tract, it must be as accurate as possible insight into the problem. Imaging technology allows to look into the body, unfortunately for example lung is an organ, where without contrast agent does not buy the picture. Furthermore, the methods that can be used are whole body plethysmography or, a better option, spirometry. A measurement of spirometry is performed by the pneumotachograph or the spirometry. Spirometer measures lung volumes and lung capacity. Pneumotachograph is the flow rate measuring device, but can also be used for indirect measurement of lung volumes and capacities. Spirogram is the result of spirometry measurements.
\end{abstract}

Keywords: Spirometry, lungs, function lungs parameters, digital communication, Matlab.

\section{$1 \quad$ Introduction}

In the past it was possible to perform spirometer only in medical facilities. Older spirometers are voluminous, have high maintenance and their measurement capabilities are very limited. After each patient had to be the instrument properly disinfected to prevent transmission of bacteria. Over time, the dimensions of the device and thus diminished their demands for service and maintenance. The coup came with the advent of pneumotachograph. They also want to specify multiple parameters of lung and especially sharply reduced the size of the device itself. Now, using simple instruments, measurements can be made in domestic environments. Measurement results are displayed on the LCD display device or on a computer screen [8].

This paper describes how to create a demonstration and simple devices for spirometer. It can find usage in a professional environment or in an education area in an university. Modern digital sensor was used with excellent high sensitivity, low power consumption and preprocessing options. It was also used Matlab programming options.

\section{Methods}

For spirometry is possible to use several different methods like water spirometer, drybellowed wedge spirometer or fully electronics spirometer, typically. Electronic 
spirometers have been developed that compute airflow rates in a channel without the need for fine meshes or moving parts. They operate by measuring the speed of the airflow with techniques such as ultrasonic transducers, or by measuring pressure difference in the tube [5]. These spirometers have greater accuracy by eliminating the momentum and resistance errors associated with moving parts such as windmills or flow valves for flow measurement. They also allow improved hygiene between patients by allowing fully disposable air flow channels.

\section{$3 \quad$ Measuring Set}

Principle of measuring a spirometry was chosen differential manometer. Spirometer body is made up of a biological filter HEPA Light. Electronics device includes a digital component to communicate with a computer. This solution enables the processing of measured data using specialized software without having to perform other calculations.

The sensor is a product of Swiss company Sensirion (see Tab. 1). The sensor output is digital, the $\mathrm{I} 2 \mathrm{C}$ bus. Temperature calibration is automatically done by the sensor and electronics output is already linearized. Influence of initial offset aging of the material is given less than $0.1 \mathrm{~Pa}$ per year. The default sensitivity resolution of 12 bits (can be 9 to 16 bits) is given $0,2 \mathrm{~Pa}$. The sensor is recommended, inter alia, in health care. This sensor offers the best fit of desired parameters and especially its digital output, thus allowing easier processing in the computer.

The measurement is started by breathing into the spirometer. Non-electric value is converted to digital signals by sensor. [6]

Table 1. Sensor parameters

\begin{tabular}{|l|c|}
\hline Power supply & $3-3,6 \mathrm{~V}$ for $<6 \mathrm{~mA}$ \\
\hline Measurement range & $-500 \mathrm{~Pa} \div 500 \mathrm{~Pa}$ \\
\hline Response time & $4.6 \mathrm{~ms}$ \\
\hline Temp. calibration range & $0{ }^{\circ} \mathrm{C}-50{ }^{\circ} \mathrm{C}$ \\
\hline I2C working frequency & $100 \mathrm{kHz}(\max .400 \mathrm{kHz})$ \\
\hline
\end{tabular}

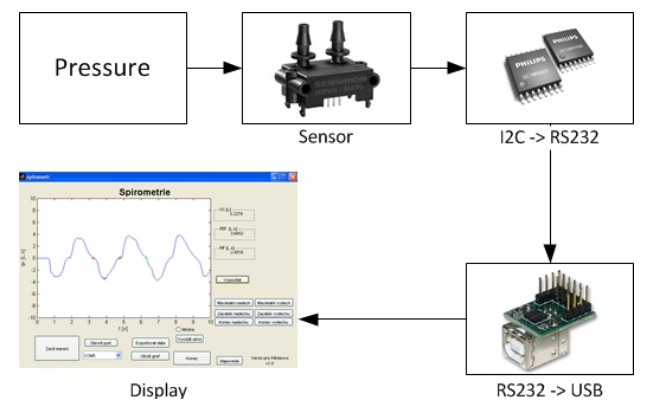

Fig. 1. Measuring set 
The digital signal is converted into comprehensible forms for serial communication. The computer information is drawn from the serial line and the measurement is complete interpretation of the measured values. Result can be interpreted as a graph or directly calculated values of lung parameters. The measurement block diagram is displayed in Fig 1.

For easier interpretation of the results, the mathematical program Matlab is used. Matlab allows contact the programming elements and mathematical operations. Facilitates the work by omitting the definition of computing and thus automate the processing of values measured. Ideal measurement software should performs satisfy several following requirements:

- easy operation

- error - free functionality (clean code)

- the possibility to save results

The software (see Fig. 2) is developed as multiplatform for Windows and Mac OS X. For a smooth running program, you must have installed the virtual port driver and the Matlab version at least 2008 for Windows or for Mac OS X, Matlab 2009. For both operating systems, 32-bit and 64-bit architectures are supported.

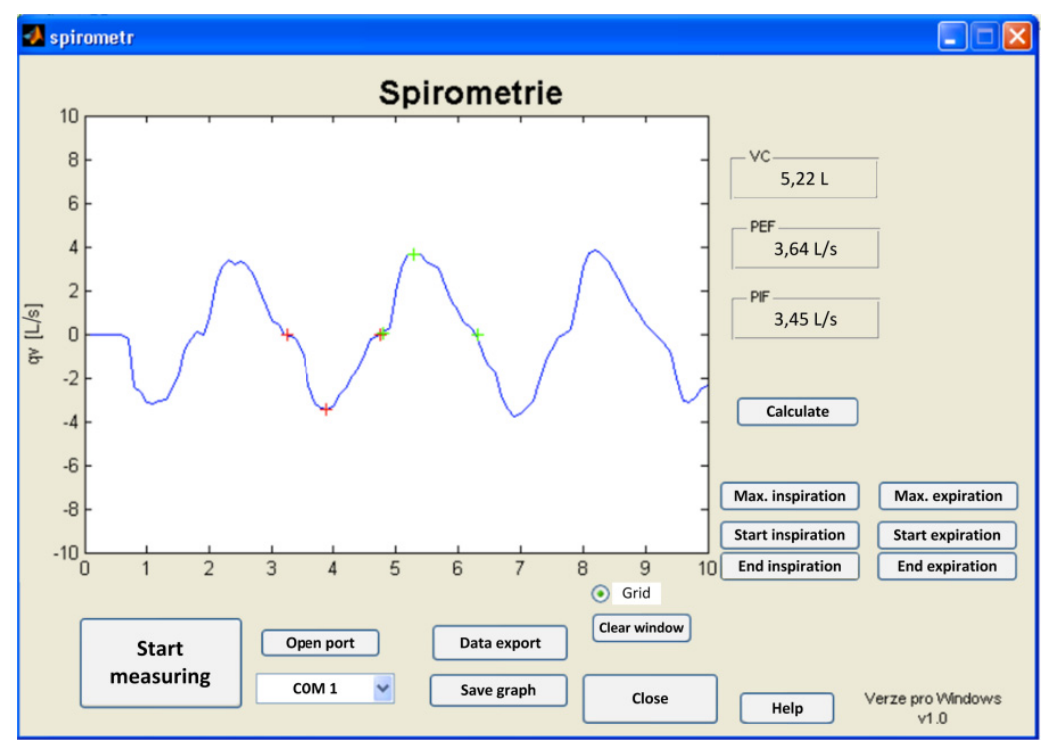

Fig. 2. Software window

\section{Calibration}

The value of the pressure difference $\Delta p$ is linearly dependent on the volume $q_{v}$ and size of air flow resistance $R$ (see (1)). 


$$
\Delta p=p_{2}-p_{1}=R \cdot q_{v}
$$

To calculate the correct flow of gas was needed to determine the value of air resistance. The gas flow is expressed first by equation (1) and from already adjusted equation (2) is calculated the gas flow value $q_{v}$.

$$
q_{v}=\frac{\Delta p}{q_{v}}
$$

The value of pressure difference and flow rate were known during the calibration. Therefore equation (2) was modified into (3).

$$
R=\frac{\Delta p}{q_{v}}
$$

The gas rate was simulated using a phantom of an air, in the range of $0,3 \mathrm{~L} \cdot \mathrm{s}^{-1}$ to $0,85 \mathrm{~L} \cdot \mathrm{s}^{-1}$. Phantom of air was connected to the spirometer input and the differential pressure was sensed by a computer with a period of $10 \mathrm{~s}$. Readout pressure was calculated by averaging the readings over one minute.

Next table (see Tab. 2) shows results from calibration. The average air resistance $R$ was calculated as the mean of the measured resistance and is equal to $0,2029 \mathrm{~Pa} \cdot s \cdot L^{-1}$. This value was set as the resistance to air flow. Then it is easy to compute unknown air flow by (2) because $\Delta p$ is measured and $R$ is known from previous computation.

Table 2. Computed resistance $\mathrm{R}$

\begin{tabular}{|c|c|c|}
\hline$q_{v}\left[L \cdot s^{-1}\right]$ & $\Delta p[P a]$ & $R\left[P a \cdot s \cdot L^{-1}\right]$ \\
\hline 0,30 & 0,0325 & 0,14 \\
\hline 0,35 & 0,0490 & 0,1083 \\
\hline 0,40 & 0,0653 & 0,1632 \\
\hline 0,45 & 0,0817 & 0,1816 \\
\hline 0,50 & 0,0980 & 0,1960 \\
\hline 0,55 & 0,1143 & 0,2078 \\
\hline 0,60 & 0,1307 & 0,2178 \\
\hline 0,65 & 0,1470 & 0,2262 \\
\hline 0,70 & 0,2251 & 0,3216 \\
\hline
\end{tabular}

\section{$5 \quad$ Testing}

Test was made for all functions of the device and measurement software. Readings from the program were compared with values measured on the spirometer made by ZAN. The spirometer ZAN100 (the principle of differential pressure) was used for 
testing. There have been several controlled test measurements. The next table (see Table 3) shows results from testing.

The difference of the reference level and minimum inspiration values is equal to the peak of inspiration flow (PIF) in liters per second. By integrating the volumetric flow across the interval of maximum inspiration is received a value of vital lung capacity in liters. See (4) where $t_{1,2}$ is start and end of inspiration, $q_{v}$ is volume flow and $V$ is vital lung capacity.[9][10]

$$
V=\int_{t_{1}}^{t_{2}} q_{v} d t
$$

Table 3. Compare between SDP610 and ZAN100

\begin{tabular}{|c|c|c|}
\hline Parameters & SDP610 & ZAN100 \\
\hline PEF & $3,6 L \cdot \mathrm{s}^{-1}$ & $3,8 \mathrm{~L} \cdot \mathrm{s}^{-1}$ \\
\hline $\mathrm{PIF}$ & $3,4 \mathrm{~L} \cdot \mathrm{s}^{-1}$ & $3,6 \mathrm{~L} \cdot \mathrm{s}^{-1}$ \\
\hline $\mathrm{VC}$ & $5,2 \mathrm{~L}$ & $5,5 \mathrm{~L}$ \\
\hline
\end{tabular}

Next figure (see Fig. 3.) shows the record along breath made from one inspiration and expiration, and an intensive inspiration and expiration.

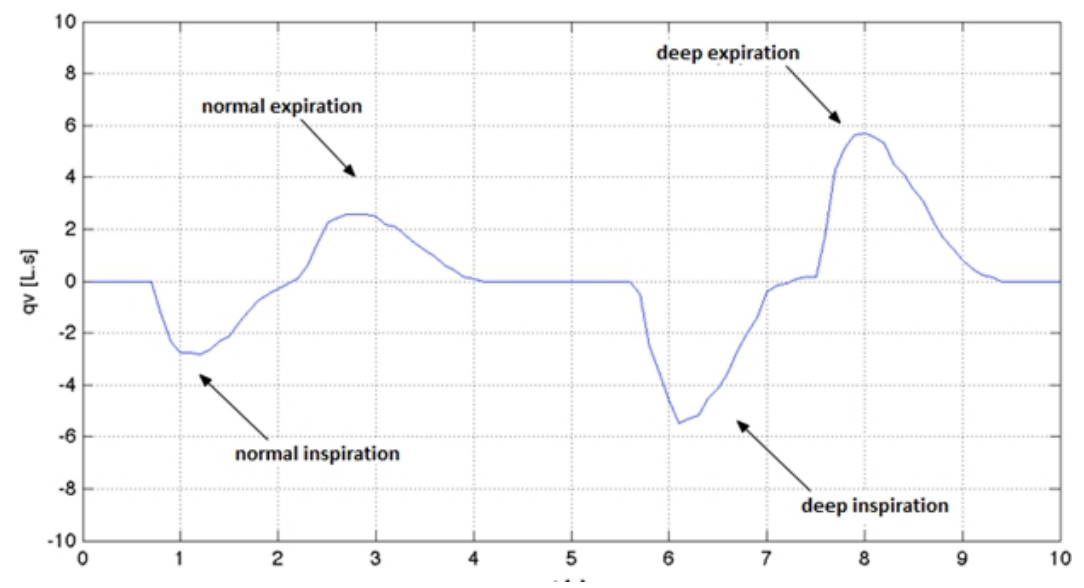

Fig. 3. Air flow along breath and intensive breath

\section{Conclusions}

Method of measurement using differential manometer was chosen. Durability and reliability of the spirometer are improving by no moving parts are needed during the measurement. For compiling of the devices were used materials from health care, or 
materials wholesome. HEPA filter Light is used as the air resistance to the spirometer. It also serves as a barrier to the spread of bacteria. Spirometer is designed for easy using with the hygienic mouthpiece.

Electronic part of the device was selected for processing of signal on the computer. As differential sensor, the digital sensor SDP610 from the company Sensirion has been selected. With the compensation capabilities of this sensor is not necessary to further modify the signal. The signals from the sensor are transferred via serial communication line and then sent to a computer. In the computer was created software for processing.

Sensor SDP610 proved to be very suitable sensor with potential for use in medical applications.

Acknowledgements. The work and the contribution were supported by the project Student grant agency "Biomedical engineering systems VIII" and TACR TA01010632 "SCADA system for control and measurement of process in real time".

Has been elaborated in the framework of the IT4Innovations Centre of Excellence project, reg. no. CZ.1.05/1.1.00/02.0070 supported by Operational Programme 'Research and Development for Innovations' funded by Structural Funds of the European Union and state budget of the Czech Republic.

\section{References}

1. Cerny, M., Penhaker, M.: Wireless Body Sensor Network in Health Maintenance system. Journal Electronics and Electrical Engineering IX(9), 113-116 (2011), doi:10.5755/j01.eee.115.9.762, ISSN 1392-1215

2. Spišák, J., Imramovský, M., Penhaker, M.: Senzory a snímače v biomedicíně, 117 p. VŠB-Technická univerzita Ostrava, Ostrava (2007) ISBN 978-80-248-1607-4

3. Augustynek, M., Penhaker, M., Vybiral, D.: Devices for position detection. Journal of Vibroengeneering 13(3), 531-523, ISSN: 1392-8716

4. SDP610 [online]. Sensirion: The Sensor Company (2009), http: / / www . sensirion. com/ en/pdf/product_information/Datasheet_SDP600series_differential_ pressure_sensor.pdf (cit. November 03, 2010)

5. Penhaker, M., et al.: Lékařské diagnostické př́istroje: Učební texty. 1. vydání, 332 p. VŠB - Technická univerzita Ostrava, Ostrava (2004) ISBN 80-248-0751-3

6. SirXpert [online]. Become an expert in spirometry, http://spirxpert.com/ (cit. April 22, 2011)

7. Spirometrie.info [online]. World of spirometry, http://www.spirometrie.info (cit. April 20, 2011) 